\title{
Os efeitos da hanseníase em homens e mulheres: um estudo de gênero
}

\author{
The effects of Leprosy on men \\ and women: a gender study
}

Maria Helena Pessini de Oliveira 1

Geraldo Romanelli 2

\footnotetext{
1 Escola de Enfermagem de Ribeirão Preto, Universidade de São Paulo. Av. Bandei rante 3.900, Ribeirão Preto, SP 14040-902, Brasil.

2 Faculdade de Filosofia Ciências e Letras de Ri beirão Preto, Universi dade de São Paulo. Av. Bandeirante 3.900, Ribeirão Preto, SP 14040-902, Brasil.
}

Abstract On the basis of social representations, we detected gender differences in family and individual living experiences for people with Hansen's disease (HD, or leprosy) in a sample of 202 HD patients ( 132 men and 70 women) enrolled in a public treatment and control program in Ribeirão Preto, São Paulo State. Information was gathered in two stages. First, the HD patients responded to a structured questionnaire, and second, the authors heard reports from 10 men and 10 women on their daily living situations. Data indicated that the disease recei ves different representations by men as compared to women in the different social groups. HD was found to be a source of gender imbalance, further aggravating existing soci ocultural inequalities and creating new sources of biopsychosocial and economic harm, in addition to the stigmata weighing on individual patients. Results should help reorient treatment and control programs aimed at the social rehabilitation of HD patients, besi des serving as a paradigm for future research.

Key words Leprosy; Gender; Social Representation

Resumo Por meio das representações sociais, detectamos di ferentes experiências de viver a hanseníase no contexto familiar e individual de uma população constituída por 202 hansenianos (132 homens e 70 mulheres), inscritos no programa de controle e tratamento dos serviços de saúde de Ri beirão Preto. Duas etapas para coletas de informações foram realizadas. Na primeira, os hansenianos responderam a um questionário com perguntas estruturadas; na segunda, foram ouvi dos relatos de situações vi vidas no coti di ano de dez homens e mul heres. Os dados revel aram que a doença mobilizou representações diferentes entre os homens e mulheres nos diferentes grupos sociais. A hanseníase representou um desequilíbrio entre os gêneros, acentuando as desigualdades já existentes no campo sócio-cul tural e criando novos problemas responsáveis pel os prejuízos bio-psico-sociais e econômicos, além dos estigmas que pesam sobre os indivíduos. Tais resultados devem reorientar os programas de control e e tratamento, visando à recuperação social dos hansenianos, etambém servir de paradigma a novas investi gações.

Palavras-chave Hanseníase; Lepra; Sexo; Representação Social 


\section{Introdução}

Vários indicadores motivaram a realização deste estudo, dentre eles a situação vigente da hanseníase no País, a qual continua com uma tendência crescente, trazendo resultados desastrosos em decorrência das condições sociais e econômicas em que vive a maioria dos seus portadores; acrescenta-se, ainda, o desconhecimento que continua envolvendo a doença, bem como a escassez de informações quanto aos efeitos que a hanseníase provoca em homens e mulheres.

A hanseníase é uma enfermidade de importância nacional, colocando o Brasil em segundo lugar no mundo pelos elevados coeficientes de incidência e prevalência, comprometendo homens e mulheres, acarretando sérios prejuízos de ordem bio-psico-social e econômico (Glatt \& Alvin, 1995; OMS, 1993).

Eliminar a hanseníase como problema de saúde pública é a meta da OMS, prevista para o ano 2000, e um desafio para as autoridades brasileiras, que vêm intensificando suas ações junto aos serviços de saúde do país. Algumas regiões, no entanto, continuam com sérias dificuldades para desenvolver o programa de controle e tratamento da hanseníase, necessitando intensificar esforços na luta contra o estigma social e na conscientização dos profissionais da área da saúde (Nogueira et al., 1995).

As investigações realizadas revelam que a doença continua a incidir em maior proporção entre homens, embora nos últimos anos a diferença entre os sexos tenha diminuído, acometendo mulheres em plena capacidade de reprodução e produção laboratorial, sem, todavia, explorar mais intensamente as conseqüências que a hanseníase tem ocasionado diferentemente entre eles.

Identificar os diversos efeitos da hanseníase na variável gênero constitui mais uma estratégia de investigação para compreender como os indivíduos vivem a situação da doença nas diferenças biológicas e sociais e no contexto social específico com várias complexidades que os envolvem.

Para efetuar o estudo da hanseníase sob a ótica de gênero, buscou-se nas representações sociais o embasamento para compreender o senso comum, ou seja, a realidade social do cotidiano dos doentes e a relação com a enfermidade. A identidade de gênero, portanto, foi uma variável importante que permitiu analisar essas relações e contextualizar o igual e desigual dos enfermos.

O enfoque gênero, em saúde, permite reconhecer a importância da vida familiar, espaço onde transcorre grande parte da vida das muIheres e dos homens, nos diferentes períodos do ciclo vital, responsáveis pelo desenvolvimento das práticas de socialização, saúde e reprodução social (Gomez, 1993; Rios, 1993).

Em matéria de saúde, as mulheres e os homens apresentam diferenças significativas entre si não só em termos de necessidades específicas, mas também de acesso à proteção à saúde. Sabe-se que a doença pode ser um fator de desencadeamento de mudanças na estrutura da família, colocando a mulher, acometida pela hanseníase, em desvantagem pela duplicidade da discriminação que ela sofre, ou seja, ela é discriminada em função do gênero a que pertence e pelo fato de estar doente.

Buscar compreender quais são os principais efeitos que a hanseníase provoca em cada gênero constituiu o objeto principal desta investigação, acreditando-se que o resultado deste trabalho possa contribuir com a difusão de medidas educativas por parte dos serviços de saúde, uma vez que as pessoas mantêm diversas crenças e atitudes preconceituosas acerca da doença, influenciadas, em parte, por seu nível educacional e, em parte, por seus antecedentes sócio-culturais.

\section{Metodologia}

Esta pesquisa foi efetuada durante os anos de 1994 e 1995, no Município de Ribeirão Preto, Estado de São Paulo, Brasil. Em dezembro de 1994, contava com 649 hansenianos (447 homens e 202 mulheres), em registro ativo, no programa de controle e tratamento da doença, distribuídos nos serviços de saúde que oferecem atendimento aos portadores de hanseníase.

Os serviços de saúde contam com médicos especialistas em dermatologia que, além de diagnóstico clínico, fazem o acompanhamento da evolução da doença nos pacientes, juntamente com a equipe de profissionais da área da saúde que auxiliam nas orientações, assistência e controle da medicação e nas ações educativas. A terapêutica, em todas as formas clínicas, é realizada em nível de ambulatórios, de acordo com os critérios do programa de controle e tratamento do Ministério da Saúde.

A população foi estratificada de acordo com os critérios de diagnóstico clínico e sexo. Inicialmente, o tamanho da amostra foi fixado levando-se em consideração o número de muIheres em registro ativo (202), e a seguir calculou-se a proporção de homens e mulheres com seus respectivos diagnósticos clínicos. Desta forma, foram incluídos na amostra 132 ho- 
mens ( 12 da forma clínica indeterminada, 19 tuberculóide e 101 virchowiano ou dimorfo) e 70 mulheres (12 da forma clínica indeterminada, 12 tuberculóide e 46 virchowiano ou dimorfo). Fixada esta amostra, os hansenianos entrevistados foram selecionados por conveniência. A idade variou entre 15 a mais de 60 anos, concentrando a maior freqüência entre 31 a 60 anos (66,32\%).

Quanto ao diagnóstico, 72,77\% da população selecionada apresentavam forma clínica virchowiana, seguida de tuberculóide e indeterminada (15,34\% e $11,88 \%$ ). A maioria dos sujeitos $(71,78 \%)$ recebem o esquema da multidrogaterapia; são casados (67,82\%); residem na cidade de Ribeirão Preto há mais de dez anos no mesmo endereço (75,74\%); são católi$\cos (84,65 \%)$; vivem com famílias numerosas com três ou mais filhos (54,43\%); não concluíram o primeiro grau básico de escolaridade (64,35\%); trabal ham como assalariados com renda familiar mensal entre três a seis salários mínimos (72,00\%) e não sabem de quem pegaram a doença $(59,90 \%)$. Com relação à habitação, a maioria dos hansenianos entrevistados (51,9\%), residem em casa própria e financiada (tipo conjunto habitacional), com até cinco cômodos, localizadas na periferia da cidade em condições mínimas de conforto e higiene, abrigando uma média de 5,3 pessoas. Os demais vivem em casas alugadas e emprestadas.

\section{Procedimento e instrumentos de coleta de dados}

O trabalho foi desenvolvido em dois conjuntos de procedimento. No primeiro, por meio de um questionário com perguntas estruturadas e testadas anteriormente, foi caracterizada a população de estudo segundo idade, sexo, procedência, estado civil, número de filhos por pessoa, grau de escolaridade, ocupação atual, situação trabalhista, composição familiar e dados relativos à moradia. Buscou-se, assim, situar homens e mulheres portadores de hanseníase dentro do contexto social em que se encontram. As entrevistas foram realizadas pelo próprio pesquisador, enquanto os portadores de hanseníase aguardavam pelo atendimento médico de rotina. Os dados obtidos foram posteriormente tabulados e analisados usando recursos estatísticos de freqüência absoluta e relativa. As tabelas foram testadas através do método do X2 (Qui-Quadrado), para verificar associações entre as variáveis sexo. A hi pótese Ho foi rejeitada quando o nível de significância ( $p)$ foi inferior a 0,05 .
No segundo procedimento, foram gravados relatos de situações vividas no cotidiano de dez homens e dez mulheres portadores de hanseníase da população estudada, selecionados por conveniência. Os depoimentos foram transcritos e anal isados através de categorias empíricas: impacto da doença, aparência do doente, relacionamento conjugal/apoio e trabalho. Estas categorias foram trabal hadas valendo-se da análise das representações sociais, e o aspecto gênero entrou como uma variável, permitindo contextualizar o igual e desigual dos indivíduos com hanseníase.

\section{Resultados}

Configuração da hanseníase em Ribeirão Preto

Com base nos dados quantitativos, constatamos que as experiências vivenciadas pelos portadores de hanseníase se diferenciam, segundo os gêneros.

Os testes estatísticos revelaram diferenças significativas entre os sexos. As mulheres tendem a ficar nas categorias de solteira, separadas e viúvas; a residir por mais tempo no mesmo endereço; são mais religiosas e freqüentam com assiduidade os cultos religiosos; convivem mais com parentes e filhos do que com maridos e companheiros; ocupam-se com atividades domésticas sem remuneração e direitos à seguridade social; possuem grau de escolaridade inferior ao dos homens e apresentam uma média de renda familiar mensal de 3,3 salários mínimos.

Os homens tendem a estar mais na categoria de casado/amigado, convivendo com esposa e/ ou companheira e filhos; apesar de religiosos, não freqüentam os cultos religiosos; contribuem com a quase totalidade do orçamento familiar; trabalham regularmente exercendo atividades salariais com direito ao auxílio da seguridade social, com renda familiar mensal de seis salários mínimos por mês; apresentam um nível de escolaridade acima do básico, primeiro grau completo.

O número de homens que se aposentam em decorrência da hanseníase é superior ao das mulheres, pois estas nem sempre são registradas em carteira. A maioria das mulheres contribuem com o orçamento doméstico independente da idade e somente quatro delas recebem aposentadoria por tempo de serviço.

Embora a maioria dos portadores de hanseníase estejam recebendo tratamento poliquimioterápico, encontramos uma freqüência 
considerável de mulheres com esquema convencional (37,14\%). Essa diferença está relacionada à preferência das mulheres, evitando com isso a alteração da pigmentação da pele, comprometendo sua estética, tão repelida por elas. Outro motivo apontado foi indicação médica.

Com relação à regularidade da freqüência dos doentes ao serviço, os dados revelaram que $70,0 \%$ das mulheres são mais assíduas aos retornos médicos do que os homens $(59,84 \%)$. Quanto à irregularidade ao tratamento, os homens justificaram as suas ausências como: esquecimento do dia do retorno médico; presença de reações indesejadas, alegando que os remédios estavam fazendo mal; credibilidade na doença; preferência pela bebida alcoólica e impossibilidade de faltar ao serviço. As mulheres apontaram como principal impedimento as reações adversas, deixando-as impossibilitadas de comparecer ao serviço, seguidas de esquecimento. Neste caso, ocorreu uma inversão de valores nas justificativas de ausências ao serviço e ao gênero.

A ingestão da medicação por longos meses é um dos fatores que contribui com o abandono e irregularidade do tratamento dos portadores da hanseníase. É necessário muito apoio e incentivo por parte da família. Os serviços de saúde devem envolver os familiares do hanseniano no controle e tratamento dos seus doentes, despertando-Ihes a responsabilidade do autocuidado e da manutenção de sua saúde. Devem treinar as mulheres do núcleo familiar para ajudarem no cuidado com a medicação, cobrança da assiduidade dos retornos médicos, controle dos contatos e prevenção das lesões incapacitáveis, uma vez que são elas as principais responsáveis pela assistência primária à saúde.

Detectamos no estudo uma freqüência de $24,2 \%$ dos hansenianos de ambos os sexos que residiam em outras cidades; os homens mais preocupados com as questões econômicas ligadas ao emprego, gerador do sustento familiar, as mulheres manifestam vergonha de serem apontadas como 'leprosas', com medo da rejeição social.

Entre os portadores de hanseníase estudados, $64,4 \%$ dos homens e $51,4 \%$ das mulheres ignoravam o foco inicial de sua doença. A maioria das mulheres que desconheciam o foco da hanseníase estavam inseridas no mercado de trabalho fora do lar, ficando expostas ao contágio extradomiciliar. Segundo os dados apontados nos estudos de Andrade (1990) e Glatt \& Alvim (1995), nos últimos anos vem aumentando a incidência de mulheres portadoras de hanseníase.
Entre os portadores de hanseníase que conhecem o foco inicial da doença, apontaramse seus familiares consangüíneos (pai, mãe, avós e tios) como os transmissores da enfermidade. Por outro lado, houve diferença entre os gêneros quanto às demais fontes de transmissão da enfermidade: $23,5 \%$ das mulheres apontaram seus maridos como responsáveis pelo repasse da doença e $11,7 \%$ adquiriram hanseníase dos sogros e cunhados. Dentre os homens, $12,6 \%$ assumiram a responsabilidade de terem passado a doença para suas esposas e filhos.

Os entrevistados $(54,2 \%$ das mulheres e $45,7 \%$ dos homens) apontaram outras enfermidades associadas à hanseníase, como: hipertensão arterial (mais expressiva entre as muIheres); úlceras gástricas; epilepsia; doenças sexualmente transmissíveis (sífilis, gonorréia e HIV); doença de Chagas; diabetes; tuberculose; dengue; escabiose; efisema e outras. A pobreza, as más condições de vida, de moradia, a desnutrição, o estresse favorecem e acentuam as enfermidades já existentes, sejam infectocontagiosas ou não.

\section{As representações do impacto da hanseníase}

O impacto provocado pela doença, sem dúvida, interfere no cotidiano dos indivíduos que representaram a hanseníase como uma ameaça constante da incerteza do sucesso do tratamento, pois a condição do doente já é, por 'pré-conceito', marcada por sofrimento, abandono, deformidades e problemas psicossociais que inevitavelmente acabam por ocorrer, agora por preconceito de ordem social.

As mulheres foram mais dramáticas, descrevendo que a doença provocou vergonha, culpa e o desejo de morrer: "Mesinto arrasada, muito triste com esta situação, tenho culpa, uma dor no peito, uma vontade de chorar, minha vida acabou, eu queria morrer (...) fiquei viva por fora emorta por dentro" (Y., 49 anos).

O conflito entre o desempenho do papel de gênero (deveres e obrigações) e as limitações físicas desencadearam sentimento de culpa, daí a busca do perdão na religião como um meio para aliviar o impacto negativo da doença. A crença religiosa parece constituir um poderoso lenitivo para os indivíduos enfrentarem aflições físicas e emocionais; conforme Geertz (1978) esclarece, a crença não evita o sofrimento, mas dá sentido e significado aos acontecimentos.

As mulheres se apegam à religião como fonte de apoio e compreensão, e a expiação dos diferentes rituais, dependendo da crença preponderante de cada uma, passa a ser a so- 
lução alternativa para se livrar do castigo de que julgam ser merecedoras. Loyola (1994:78), num estudo sobre médicos e curandeiros, encontrou na representação dos entrevistados que "estar doente é estar afastado de Deus (...) e que Deus não é a causa, mas tem o poder de provocar a doença".

Assim sendo, neste estudo, a busca da religião foi marcante, sobretudo entre as mulheres como podemos observar em alguns dos depoimentos:

"Quando descobri quetinha a doença, queria me suicidar, queria de todo o custo morrer, não trabalhava (...) não queria ter culpa, foi um horror (...) daí por diante meapeguei com Deus (...) até hoje sou devota, vou três vezes por dia na igreja. Fiz promessa para toda a vida. Entreguei meu filho a Deus, meu único filho homem e caçula (...) ele está estudando, vai ser padre." (M., 49 anos)

"Foi castigo (...) por isso vou à igreja todos os dias (...) sou devota de Nossa Senhora e só Ela pode me curar." (V., 25 anos)

As mulheres se preocupam com as deformidades, uma vez que as lesões incapacitáveis provenientes da hanseníase, além de tornarem visível a doença, podem contribuir com decadência no cotidiano, pondo em risco seu espaço, seja dentro da família ou no trabalho. O não-cumprimento das suas funções dentro da família mostra a 'incapacidade' da sua administração doméstica e do cuidado com os fiIhos, motivo para serem abandonadas pelos maridos ou companheiros. Resulta daí o desgaste emocional e a sensação de que foram amputadas dos atributos de mulheres competentes e capazes de realizar as tarefas que lhes são atribuídas, tanto dentro, como fora do ambiente familiar. O conflito entre o desempenho do papel de gênero e a limitação física desencadeiam sentimentos de culpa que também podem estar relacionados às crenças culturais aprendidas durante a socialização dos indivíduos no contato com seu meio ambiente (Whitaker, 1995; Vlassof \& Bonilla, 1993).

Os homens representaram o impacto da doença com revolta, preocupação, nervosismo, desconfiança, raiva, medo e alguns com indiferença. O reconhecimento da doença por eles significou uma ameaça ao papel de provedor da sobrevivência familiar, além do desapontamento, uma vez que sua 'força' foi ameaçada, representada por eles como fraqueza, desânimo, perda da potência sexual. "A mulher fica cobrando, briga comigo, fala quearrumei outra, minha vida mudou ficou um inferno." (L., 34 anos)

A 'invisibilidade' da doença ocasiona desconfiança, levando os homens a questionarem, mais do que as mulheres, a fidedignidade do diagnóstico, do tratamento, da assistência e dos serviços públicos, motivos utilizados para justificarem as irregularidades no controle e tratamento da hanseníase; utilizam também excessivamente bebidas alcoólicas como fuga para os seus problemas. "Gosto de beber umase outras e com remédio não dá (...) o álcool mata o bicho (...)." (G., 49 anos)

Por outro lado, os homens deixaram transparecer que a experiência de estar doente foi motivo para reflexões sobre a reestruturação de suas vidas, um pensar positivo no futuro, indo em busca do tempo perdido, num gesto de esperança, conforme esclarece o depoimento: "Procuro levar a vida mais a sério e saborear mais o quefaço" (D., 47 anos)

Pode-se observar que o impacto da doença foi representado pelos hansenianos (ambos os sexos) de acordo com o meio social, econômico e cultural de cada um.

\section{$\underline{\text { Representação sobre a aparência }}$}

Os pacientes entrevistados manifestaram desconforto pela alteração da aparência decorrente dos efeitos da medicação e das reações provocadas pela doença. Muitas vezes a aparência provoca atitudes de especulação, curiosidade e preconceito no outro, bem como naquele que está servindo de espelho. A reação também foi apontada pelos hansenianos como uma das causas responsáveis pela freqüência irregular ao tratamento.

Os depoimentos apresentados revelaram que os portadores de hanseníase de ambos os sexos representaram a doença com ocorrência de sinais aparentes, responsáveis pelas mudanças tanto físicas, como de comportamento, uma vez que passaram a evitar situações que requeressem explicações. Essas situações, decorrentes, principalmente, da tendência de ocultar o diagnóstico, representam reações de auto-estigmatização, com predominância à estigmatização social.

“Minha mãe perguntava o que estava acontecendo, eu respondia que era sol. Quando eu saía, as pessoas perguntavam o que estava acontecendo, vivia dando explicações, dizendo que era mancha do sol, que era praia eisto me incomodava. As pessoas são implicantes, querem saber, são curiosas. Mas não conto o quetenho, disfarço e vou indo. Não falo pra ninguém, tenho muito preconceito. Acho que os outros também têm preconceito." (H., 50 anos)

Tanto os homens, quanto as mulheres ficaram preocupados com sua aparência, no entanto, entre elas, este sentimento foi mais 
acentuado. São dados importantes na aproximação com o paciente, pois constituem fatores de alta relevância para eles e que precisam ser respeitados, uma vez que a aparência provoca impacto negativo, seja no convívio familiar, seja fora dele, motivo de auto-rejeição e dificuldade para procurar ajuda.

As mulheres demostraram preocupação quanto à estética e medo da deformidade, sentindo-se feias e com vergonha de sua transformação, preferindo ocultar seu problema com desculpas, ou simplesmente se escondendo. A auto-estima induz o sujeito a ocultar a doença, criando desculpas e esquivando-se das perguntas (Claro, 1993).

“Minha pele era lisinha, agora está feia e manchada, eu meacho horrorosa. As pessoas vivem perguntando e eu não falo (...) perguntam seeu estou grávida ...." (Y., 49 anos)

"Tenho medo (...) minha mãe ficou deformada, esta doença mutila." (N., 41 anos)

Em nossa cultura, os padrões físicos de beleza são geralmente acoplados aos padrões morais, assim o belo é compactado com o bom e os padrões definitórios de feio induzem à idéia do mau.

A pigmentação na pele em decorrência das ações medicamentosas é representada como transtornos, uma vez que exige explicações e falar da 'sua doença', implica o risco de revelar a hanseníase. Neste estudo, as mulheres tendem a ocultar mais a doença dos familiares do que os homens. É importante que os serviços estejam atentos a este fator, orientando, esclarecendo os pacientes que estas reações indesejáveis provocadas pelos remédios fazem parte do processo do tratamento e que, com o decorrer deste, tendem a diminuir e até desaparecer.

Representação sobre o relacionamento conjugal/apoio

A família é uma unidade da sociedade onde as pessoas estão ligadas por laços afetivos e por interesses comuns, dentro da qual se dá a estruturação da reprodução e produção (Giffin, 1994). A família continua sendo uma instituição responsável pelo cuidado dos filhos. Quando um membro desta é ameaçado por uma doença, é nela que encontrará suporte para enfrentar o sofrimento.

A hanseníase ocasiona alterações e transtornos, não só na vida pública, mas também na esfera privada, acarretando conseqüências negativas na vida afetiva e sexual. A instabilidade emocional dos pacientes desencadeia um estado de crise, provocando tensões e, conseqüentemente, modificações físicas, psicológicas e sociais, resultando na desestabilização do relacionamento familiar e social. O exame das reações apresentadas pelos portadores de hanseníase, nas relações conjugais, apresenta variações conforme o gênero do doente. "Meu marido vivia brigando comigo, judiava de mim, bebia muito e acabou com tudo (...) esta doença acabou com minha vida." (V., 39 anos)

A doença, para mulheres, não é vista como empecilho pelos seus companheiros para o relacionamento sexual, mas age como barreira para receberem outras manifestações de afeto, como beijos e carícias. "A única coisa que interferiu foi que separei tudo (...) durmo na mesma cama com meu marido, mas col oco lençol separado. Meu marido faz sexo, mas não beija, ele perguntou para o médico. Faz dois anos quenão beijo meu marido eminha filha." (Z., 33 anos) A hanseníase pode dificultar a disponibilidade, a motivação das mulheres, ou por falta de interesse delas mesmas ou por auto-rejeição, mas não impede de continuar a ser fonte de prazer sexual masculino, cumprindo o papel que as representações sobre a sexualidade do gênero feminino Ihes atribui.

A recusa eventual das mulheres no cumprimento do seu papel sexual, em decorrência da exaustão física pelo excesso de trabalho, aliado ao desgaste ocasionado pela doença, pode levar os homens a satisfazerem suas necessidades fora de casa, acentuando o sentimento de rejeição, a queda da auto-estima e o medo de serem abandonadas, fato que foi comprovado.

As mulheres deste estudo se mostraram mais preconceituosas que os homens, com atitudes de auto-estigmatização, desencadeando sérios problemas no cotidiano, inclusive a discórdia e o abandono de si mesmas ou do outro.

A hanseníase, para os companheiros das mulheres doentes, não provocou a separação dos corpos, mas foi motivo para a separação de utensílios de uso pessoal como medida de prevenção ao contágio. Estas medidas constituem aparentemente paradoxo, uma vez que, com a introdução da medicação, o bacilo de Hansen deixa de ser viável e, se ocorreu uma infecção, foi antes do tratamento. São dados importantes que devem ser reforçados nas ações educativas destinadas aos portadores da doença e seus comunicantes.

Biologicamente, os homens podem sofrer agressões do bacilo de Hansen, que interfere nas células de Sertoli, provocando a esfoliação acentuada da linhagem germinativa e ruptura da barreira 'hemato-testicular', que, por sua vez, possibilita a auto-agressão à gônada. Foram constatados níveis elevados de hormônios fólico-estimulantes e luteinizantes, e baixos de 
testosterona nos pacientes virchowiano, bem como massas irregulares de bacilos dentro dos túbulos seminíferos (Arruda, 1988). Essas alterações podem levar à redução das atividades sexuais, redução da fertilidade. São alterações pal páveis, com efeitos diferentes daqueles que incidem sobre as mulheres. Os homens são reconhecidos como sujeitos ativos do ato sexual e a ausência da ereção, seja por dor na região testicular, seja por presença de edema, induz a sérios problemas, porque realizam representações e desencadeiam outras, uma vez que nem sempre são orientados quanto a esta mudança. As orientações, quando são feitas, esbarram nas dificuldades de acesso, uma vez que falar sobre sexualidade humana, para os profissionais de saúde, implica mobilizar suas próprias representações, despir-se de qualquer preconceito e adquirir conhecimentos. $\mathrm{O}$ assunto sobre sexualidade deve fluir naturalmente.

Diante do fracasso sexual, os homens apontam como fator responsável a medicação, a idade e até transferem para as mulheres a sua culpa. A disfunção sexual constitui um problema maior, principalmente para os mais jovens, pois "a identi dade de gênero exige a sua identidade heterossexual ativa", descreve Giffin (1994). A ausência do cumprimento do ato sexual pelos maridos hansenianos coloca em questão a fidelidade, daí surgindo a desconfiança e a ameaça ao espaço social dentro da família, conforme observado no depoimento: “Minha mulher fica cobrando, fica brigando, fala que arrumei outra, minha vida ficou um inferno" (D., 34 anos).

Em face da instabilidade emocional provocada pela hanseníase, o apoio do cônjuge (marido ou esposa), dos filhos, pais e irmãos é importante no enfrentamento da doença e no sofrimento pela enfermidade.

De acordo com os depoimentos das mulheres deste estudo, pode-se perceber a dificuldade dos cônjuges em expressar apoio, permanecendo calados e até evitando falar sobre o assunto.

“Meu marido metraz aqui [paciente reside em outra cidade], já falou com o médico, mas nós não fal amos nada a respeito (...) é como se um não soubesse que o outro sabe, uma situação estranha. Eu não falo nada, ficamos em silêncio, como se nada estivesse acontecendo (...) nosso relacionamento sexual diminuiu muito depois da doença (...) el efala: vai se tratar primeiro depois a gente volta." (V., 25 anos)

Nesta investigação, as mulheres contaram mesmo com a ajuda e apoio de outras mulheres, na figura de mãe ou irmã. Em nenhum momento foi mencionado o envolvimento dos maridos ou companheiros, no cotidiano fami- liar, repartindo as preocupações e obrigações domésticas, e tampouco houve palavras de carinho, conforto e solidariedade.

Por outro lado, os homens contam com a ajuda das esposas ou das mães, já que, conforme as representações acerca do gênero feminino, cabe às mul heres a capacidade e habilidade para cuidar dos doentes. Segundo Vlassof (1993), as mulheres são consideradas provedoras do cuidado à saúde da família.

As mulheres vivem num clima de incerteza quanto à transmissão da doença para os filhos, e mesmo assim preferem ocultar destes a doença. Daí a revolta e a decepção deles quando descobrem que as mães estão doentes.

Os efeitos biológicos provocados pela hanseníase são diferentes, de acordo com o gênero, trazendo prejuízos para os homens e muIheres; a esses prejuízos reais devem ser acrescentados todos aqueles que são produtos de representações resultantes do seu meio sócioeconômico e cultural.

\section{Representação sobre o trabalho}

Não obstante a baixa remuneração, as mulheres contribuem para o orçamento da família. A maioria das mulheres doentes são casadas e têm filhos, não contando com o auxílio da seguridade social, uma vez que trabalham como autônomas ou sem registro de trabalho, o que as coloca em situação precária. No primeiro caso, o aparecimento da doença, acompanhado de manifestações físicas, pode dificultar suas atividades no espaço doméstico; no segundo caso, podem ser despedidas sumariamente, quando a moléstia se manifesta e se torna pública no local de trabalho.

Neste estudo, encontramos mulheres que preferiram abandonar o emprego, antes mesmo de serem identificadas como doentes, 0 mesmo não ocorrendo com os homens.

Alguns homens relataram dificuldades no trabalho com o aparecimento da doença. Além das manifestações físicas, a indisposição, preocupação, limitaram sua capacidade produtiva, que, associadas à ausência mensal ao trabalho para o tratamento, colocaram em risco a continuidade no emprego. Assim, muitos preferiram ocultar sua doença, para não serem despedidos ou aposentados precocemente.

\section{Discussão}

Sucede que a doença em questão impele as pessoas, independente do gênero, a viverem situações comuns, entretanto, a ela associadas, 
surgem marcas que são produzidas ou reforçadas pela sociedade, extrapolando-se dos corpos para o âmbito das relações que são estabelecidas entre pessoas 'sadias'. Assim, a experiência de adoecer, há séculos, vem sendo associada aos estigmas que são imputados aos seus portadores.

A hanseníase mobilizou representações diferentes entre os gêneros masculino e feminino e nos diferentes grupos sociais em que estão inseridos os portadores da moléstia.

Identificar e analisar as representações associadas ao gênero podem contribuir com os profissionais da saúde para maior adequação da assistência ao paciente no controle e tratamento da doença, desde a abordagem inicial do hanseniano e seus familiares, bem como durante seu tratamento. Tal procedimento leva-os a compreender que as alterações físicas, mais freqüentes nos homens, estão relacionadas à hanseníase e que as medicações podem desencadear reações indesejáveis, que tendem a diminuir com o avanço do tratamento.

Para os homens deste estudo, as representações da doença não ficaram só no campo sócio-cultural e fisiológico, ocorreram também no campo anatômico. Observamos alterações reais em razão da doença, e também como elas podem ser vistas à luz das representações específicas. Estas diferenças apontadas merecem maiores estudos. Compreender as mudanças físicas, não só no homem, como na mulher, é importante para direcionar as orientações específicas a cada gênero, aliviando a tensão e propiciando o entendimento científico das conseqüências da hanseníase, contribuindo, assim, com sua aceitação.

A sexualidade dos hansenianos é, sem dúvida, afetada e pouco valorizada pela equipe de saúde responsável pelas orientações e pelo cuidado com o paciente. Os homens representaram desapontamento diante da ameaça a sua virilidade, desencadeando agressividade, medo, desconfiança, rejeição à medicação, acusando as mulheres pelo fracasso, aparentemente assumindo menos a doença do que as mulheres.

Os hansenianos devem ser abordados pelos profissionais de saúde dentro da ótica das diferenças de gênero, permitindo que aqueles exteriorizem suas preocupações, uma vez que a doença leva a uma instabilidade emocional, desencadeando crises, provocando tensões e, conseqüentemente, modificações físicas, psicológicas e sociais responsáveis, muitas vezes, pela desestabilização do relacionamento familiar e social. As ações educativas devem ser direcionadas à família, independente de quem seja o portador da hanseníase, visando à pro- moção da saúde, à prevenção e ao controle da doença, medidas que contribuem com a qualidade de vida dos indivíduos como um todo.

É imprescindível que os serviços de saúde estejam atentos à força que a mulher representa dentro da família, e os profissionais devem solicitar sua ajuda na elaboração de atividades de prevenção, controle e tratamento dos portadores de hanseníase. Mobilizar a participação das mulheres nos programas educativos na comunidade é acreditar na influência positiva que elas exercem sobre as outras mulheres. Aproximar as representações populares da hanseníase ao conhecimento científico pode surtir efeitos positivos no diagnóstico precoce da doença. Esta é mais uma estratégia para alcançar a eliminação da hanseníase para o ano 2000, meta da OMS.

Por se tratar de uma doença que não requer tecnologia sofisticada para o seu diagnóstico, a hanseníase acaba ficando em segundo plano dentro das instituições responsáveis pela formação de profissionais para a saúde. A maioria dos portadores de hanseníase manifestaram, durante a entrevista, dificuldades dos médicos em concretizar o diagnóstico, passando por várias situações constrangedoras, até chegar a um profissional capaz de efetuar o diagnóstico correto.

Além dos gastos desnecessários de tempo e dinheiro e dos prejuízos bio-psico-sociais, essas situações vivenciadas pelos hansenianos são em grande parte responsáveis pela credibilidade negativa que eles têm dos serviços de saúde, os quais devem estar atentos às manifestações de outras queixas de doenças que os hansenianos possam apresentar, procedendo encaminhamento e acompanhamento nos exames clínicos, para evitar atitudes preconceituosas por parte de profissionais distantes da problemática da hanseníase.

Para vencer a hanseníase, é necessário que ela esteja na superfície, onde todos possam vêla. Se os profissionais da área de saúde assumirem-na como uma doença que compromete homens e mulheres, cujas manifestações envolvem os aspectos sociais, culturais, econômicos e físicos, com efeitos e representações próprias de cada gênero, a moléstia como um todo poderá vir à tona e mostrar os vários níveis de complexidade, facilitando as estratégias de intervenções para sua eliminação. Sendo assim, urge que a hanseníase seja trabal hada com ênfase, não se limitando apenas aos aspectos biológicos, mas situando-se no contexto social, econômico, cultural, psicológico e político.

Que os resultados sirvam de fontes de conhecimento e otimização da formação de re- 
cursos humanos, revertendo para os portadores da hanseníase ações educativas, minimizando o quadro do doente e da doença, servindo também de paradigma para novas investigações.

Nesta pesquisa, a hanseníase representou um desequilíbrio entre os gêneros: de um lado acentuou as desigualdades já existentes no contexto sócio-cultural; de outro, serviu como fonte desencadeadora de novos problemas responsáveis pelos prejuízos bio-psico-sociais e econômicos. Algumas semelhanças encontradas entre os gêneros podem ser configuradas por meio de dados quantitativos.

O diagnóstico provocou um impacto emocional intenso e negativo, que variou de acordo com as condições sócio-econômicas dos indivíduos, desencadeando atitudes de auto-estigmatização, perturbando a integridade psicológica dos doentes, fato mais marcante observado, neste estudo, entre as mulheres. O impacto da doença foi representado com muita emoção, deixando transparecer sofrimento e incertezas quanto ao sucesso do tratamento, influenciados pela trajetória histórica contínua da hanseníase carregada de estigma, crenças e valores atribuídos aos 'leprosos', difícil, mas não impossível de ser erradicado. A compreensão das mudanças físicas, psicológicas e sociais dos portadores da moléstia, segundo o gênero, pode minimizar o quadro negativo da doença.

As mulheres buscam na religião a solução alternativa para livrarem-se do castigo, representando a tentativa de expiação e punição, o que as leva ao desgaste emocional, à insatisfação e à sensação de que foram amputadas dos atributos de esposas ou mães competentes, capazes de realizar suas tarefas.

As mulheres deste estudo mostraram-se mais preocupadas com a aparência física, mais culpadas, punitivas, com auto-estima alterada, revelando atitudes mais preconceituosas; mostraram-se também insatisfeitas, com medo de perderem seu espaço dentro da família por abandono e rejeição, conseqüentemente submetendo-se aos caprichos e exigências do meio ambiente em que estão inseridas. Elas devem ser esclarecidas que o adoecer é um risco e não uma fatalidade, que há fatores que contribuem com o adoecimento dos indivíduos.

A hanseníase nas mulheres não constituiu impedimento no relacionamento sexual com seus maridos ou companheiros, porém foi empecilho para outras manifestações de afeto e carinho, impedindo maior aproximação. Essas atitudes foram compreendidas como rejeição e/ou auto-rejeição, motivo responsável pela discórdia e separação conjugal, levando as mu-
Iheres a assumirem a responsabilidade da manutenção e ordem familiar. É importante que os profissionais estejam alertas a estas representações, propiciando suporte emocional e alívio às dificuldades vividas no momento.

Apesar da hanseníase, as mulheres continuam a trabalhar, seja no domicílio, ou fora da esfera doméstica, cumprindo dupla jornada de trabalho, sem direitos à seguridade social, uma vez que a maioria delas executam atividades de prestação de serviços, o que impede o seu afastamento remunerado para tratamento. Quando a doença tornou-se pública, as mulheres perderam seus empregos, pois as pessoas da sociedade, de modo geral, não aceitam dentro de suas famílias uma empregada doméstica portadora deste mal.

Dentro do contexto das atribuições femininas, ou mais especificamente da esposa, é certo que ela tenderá a ficar sobrecarregada para desempenhar suas tarefas domésticas, tendo ainda que enfrentar os cuidados necessários para o tratamento da hanseníase. Por outro lado, a situação do homem, sobretudo quando ele é o chefe da família responsável, no todo ou na maior parte, pelo consumo doméstico, também é seriamente afetada quando ele é acometido pela doença.

As mulheres, enquanto contato de seus maridos doentes, procuram mais os serviços de saúde do que os homens, inclusive levando os filhos pequenos para o controle. Detectou-se que, à medida que avança a idade dos filhos dos portadores de hanseníase, mais difícil fica o comparecimento daqueles ao serviço.

A doença levou alguns homens a refletirem sobre o futuro, preocupados em aproveitar o tempo perdido, modificando seu modus vivendi; outros passaram a valorizar a família, os amigos, buscando solução, com outras mulheres, para as suas dificuldades sexuais.

Dimensionar e compreender os efeitos da hanseníase em ambos os sexos, além de suas diferenças, serviu para ilustrar como os doentes vivem e sentem a doença no contexto biopsico-social, cultural e econômico.

\section{Conclusão}

Vários estudos científicos sobre a hanseníase vêm sendo, ao longo dos anos, motivo de grandes discussões, envolvendo diversas áreas do conhecimento, desde as ciências básicas, imunologia, biologia, genética, e outras, percorrendo questões relacionadas aos aspectos médico-clínicos, epidemiológicos, de diagnóstico e de tratamento. No campo das ciências sociais, 
grupos de estudiosos vêm direcionando seu interesse na exploração desta área, buscando compreender os determinantes que afetam a saúde dos doentes, com base nos significados culturais e nas reações sociais despertadas pela doença nas diversas sociedades e no gênero através dos tempos.

\section{Referências}

ANDRADE, V. L. G., 1990. Características da Hanseníase em Área Urbana: Município de São Gonçalo, Rio de Janeiro. Dissertação de Mestrado, Rio de Janeiro: Escola Nacional de Saúde Publica, Fundação Oswaldo Cruz.

ARRUDA, H., 1988. Alterações Testiculares na Hanseníase. Tese de Doutorado, São Paulo: Escola Paulista de Medicina, Universidade Federal de São Paulo.

CLARO, L. B. L., 1995. Hanseníase: Representações sobrea Doença. Rio de Janeiro: Editora Fiocruz.

GEERTZ, C., 1978. A Interpretação das Culturas. Rio de Janeiro: Zahar.

GIFFIN, K., 1994. Esfera de reprodução em uma visão masculina: considerações sobre a articulação da produção e da reprodução, de classe e de gênero. Revista de SaúdePública, 4:23-40.

GLATT, R. \& ALVIM , M. F. S., 1995. Situação da hanseníase no Brasil e diretrizes do plano nacional de eliminação. II Censo Internacional de Leprologia. San Jose, Costa Rica. (mimeo.)

GOMEZ, E. G., 1993. Género, Mujer y Salud en las Américas. Washington: Organización Panamericana de la Salud/Organización Mundial de la Salud. (Publicación Científica, 541)
LOYOLA, M., 1994. Médicos e Curandeiros: Conflito Social eSaúde. São Paulo: Difusão Editorial.

OMS (Organização Mundial de Saúde), 1993. Weekly Epidemiological Record, 68:181-188.

NOGUEIRA, W.; MARZLIAK, M. L. C.; GONÇALVES, O. S. J. \& BRASIL, M. T. R. F., 1995. Perspectiva de eliminação da hanseníase. Hansenologia Internationalis, 20:19-28.

RIOS, R., 1993. Género, salud y desarrollo: un enfoque en construción. In: Género, Mujer y Salud en las Américas. Washington, D.C.: OPS/OMS. (Publicación Científica, 541) (mimeo.)

VLASSOFF, C. \& BONILLA, E., 1993. Gender Diferences in Determinants of Tropical Diseases: What Do We Know? Genève: Comité Directivo de Investigación Social y Economía, Programa Especial para Investigación y Entrenamiento en Enfermedades Tropicales (TDR). (mimeo.)

VLASSOFF, C., 1993. Programa de pesquisa de doenças tropicais da OMS. Consultório Médico, 4:17.

WHITAKER, D., 1995. Mulher \& Homem: O Mito da Desigualdade. São Paulo: Moderna. 